\title{
Colour change of bakery products influenced by used additions
}

\author{
Petra Č́áslavková1, Martina Bednářová ${ }^{1}$, Martina Ošt'ádalová ${ }^{1}$, Pavel Štarha ${ }^{2}$,

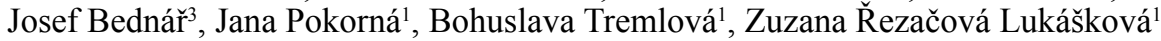 \\ ${ }^{1}$ University of Veterinary and Pharmaceutical Sciences Brno, Faculty of Veterinary Hygiene and Ecology, \\ Department of Hygiene and Technology of Vegetable Foodstuff, \\ Brno, Czech Republic \\ ${ }^{2}$ Brno University of Technology, Faculty of Mechanical Engineering, Department of Computer Graphics \\ and Geometry, ${ }^{3}$ Department of Statistics and Optimization, Brno, Czech Republic
}

Received September 1, 2014

Accepted February 25, 2015

\begin{abstract}
This study deals with the effects of selected additions of vegetable origin on the colour of whole grain breads. The colour was assessed using model samples which were made of mixtures containing various wholemeal flour types (wheat, spelt, and rye flour) and increasing amounts of additions in the form of buckwheat, oat, and barley flour. The additions were $10,20,30,40$ and 50 per cent. Colour measurement was performed instrumentally, using an image analysis method which was modified for the purposes of this study. It was found out that, regardless of the flour/addition ratio, both factors in the form of wheat, spelt, and rye wholemeal flour, and barley, oat and buckwheat flour additions and their interactions exhibited a significant influence on the colour of the bakery products $(P<0.05)$. As far as dependence of colour on the flour/addition ratio is concerned, significant differences $(P<0.05)$ were found for the following combinations: mixture of wheat flour with buckwheat, barley, and oat; mixture of spelt flour with buckwheat and oat; and mixture of rye flour with buckwheat and barley. The proposed general regression model which was created using the data obtained in the experiment, showed colour variability of more than 95 per cent.
\end{abstract}

Image analysis, whole grain breads, cereals, buckwheat, barley, oats

The most important sensory characteristics of bakery products include overall appearance, colour, structure, and taste (Van Dyck et al. 2014). In the sensory assessment of whole grain breads, the primary characteristic is colour (Ziaiifar et al. 2008) which, in consumers' minds, tends to be connected with texture, taste, food safety, elapsed time of storage, and also nutritional value (Moghaddam et al. 2014). The highest proportion of food cereals grown worldwide is used for bakery products (Pérez-Nieto 2010). Nowadays, an increased consumers' interest in whole grain breads leads to the search and implementation of new combinations of the commonly used cereals, including rye, barley, oats, corn, and also the non-grass pseudo-cereals, such as buckwheat (Liu and Scanlon 2003). In connection with introducing the new combinations of cereals and pseudo-cereals, a need arises to assess the sensory characteristics - especially colour - of products where these combinations are used.

Although the perception of colour by the human eye is highly subjective, in sensory analysis it is considered to be a crucial aspect impacting consumers' acceptance of the product (Zheng et al. 2005). Yet, no fixed range of values is available for sensory assessment of colour that would serve as an authoritative reference. However, sensory assessment cannot be applied in all instances of food assessment. The subjective nature of human visual perception (Scanlon and Zghal 2001) which is influenced by the evaluator's general physical and mental condition, can skew the assessment results (Du and Sun 2004). An introduction of the image analysis method can represent a substitute for the vision-based

Address for correspondence:

Mgr. Petra Č́áslavková

Food Production and Legislation Department

Ministry of Agriculture of the Czech Republic

Těšnov 17, 11705 Prague 1, Czech Republic
Phone: +420725240552

Email: petra.caslavkova@seznam.cz

http://www.vfu.cz/acta-vet/actavet.htm 
assessment, for the method is characterized by a high level of objectivity (Du and Sun 2004) and provides sets of relevant data. The main advantage of this method is its noninvasiveness in comparison with chemical analysis. Also, the objective nature of colour change assessment increases demand for this method among bakery producers who see it as a convenient final inspection procedure (Damez and Clerjon 2008; Girolami et al. 2013). Another benefit of image analysis lies in its high level of flexibility, reproducibility, a relatively low cost and in the scientifically advanced development of the method in the food industry (Gunasekaran 1996; Yam et al. 2004).

Among the practical uses of the image analysis method in food processing is doughnut colour assessment (Abdullah et al. 2000; Velez-Ruiz and Sosa-Morales 2003), analysis of confectionery products as well as beer, nuts, and cereals (Gerrard et al. 1996), and also of pasta and rice (Locht et al. 1997). The method can also be used for the detection of changes in food structure (Dàvila et al. 2007) which was studied by Tao et al. (1995) for the purposes of assessment of fruits and vegetables.

The objective of the present study was to adjust the method of image analysis for the assessment of bakery products colour as well as to develop a low-cost method which would be easily controllable and applicable. With the purpose to verify the method's sensitivity and applicability, an experiment was designed whose aim was two-fold: to verify the applicability of the image analysis in bakery products assessment and to assess the influence additions used (buckwheat, oat, and barley flour) on the colour of samples of whole grain breads. When combined with wholemeal flour, the above additions can increase the nutritional value and increase the colour intensity of bakery products.

\section{Materials and Methods}

In the baking experiments the following raw materials were used: wholemeal wheat flour (PRO-BIO s.r.o, Czech Republic), wholemeal spelt flour (PRO-BIO s.r.o, Czech Republic), wholemeal rye flour (PRO-BIO s.r.o, Czech Republic), buckwheat (FOODISH, s.r.o, Czech Republic), oat (EMCO, s.r.o, Czech Republic), and barley (PENAM, s.r.o, Czech Republic). All raw materials were harvested and processed in 2012. Buckwheat, barley, and oat were milled to flour using a FOSS Cemotec TM 1090, Höganäs Sweden mill, with the same coarseness setting employed. Other additions used included baker's yeast, vegetable sunflower oil, salt, and an appropriate amount of water.

\section{Bread production}

Oat, buckwheat, and barley flours were added to wholemeal flour (wheat, spelt, and rye) at the concentrations of $10,20,30,40$, and $50 \%$. The total weight of the mixture which comprised of wholemeal flour and additions of oat, buckwheat, and barley flours was $400 \mathrm{~g}$. Control samples were prepared without the additions of oat, buckwheat, and barley flours (i.e. 100\% wheat, spelt, and rye wholemeal flours). Table 1 shows the percentage of flours and additions in the samples.

The samples were produced in laboratory conditions using the straight dough method (all raw materials were mixed at once) according to recipes by Penam, s.r.o. (Czech Republic) for cereal products. To the mixture of wholemeal flour and specified amount of addition (oat, buckwheat, and barley flour), were added $16 \mathrm{~g}$ of fat,

Table 1. Composition of samples.

\begin{tabular}{lcr}
\hline Addition concentration & Wholemeal flour amount $[\mathrm{g}]$ & Addition amount [g] \\
\hline $10 \%$ & 360 & 40 \\
$20 \%$ & 320 & 80 \\
$30 \%$ & 280 & 120 \\
$40 \%$ & 240 & 160 \\
$50 \%$ & 200 & 200 \\
Control sample 1 & 400 & 0 \\
Control sample 2 & 0 & 400 \\
\hline
\end{tabular}


$16 \mathrm{~g}$ of baker's yeast, $8 \mathrm{~g}$ of $\mathrm{NaCl}$, and $240 \mathrm{ml}$ of water. The dough was kneaded in a VORWERK kneading machine (Thermomix TM31, Wuppertal, Germany) for a period of $8.5 \mathrm{~min}$. Then, it was put in a thermostat set to $30-32{ }^{\circ} \mathrm{C}$ and $75 \%$ moisture for $15 \mathrm{~min}$. Afterwards, the dough was divided into 7 bun-shaped portions, each weighing $70 \mathrm{~g}$, which were then put in the thermostatic unit to rise for $30 \mathrm{~min}$ at a temperature of $30-32{ }^{\circ} \mathrm{C}$ and $75 \%$ moisture. The risen samples were moistened with water and baked at a temperature of $250{ }^{\circ} \mathrm{C}$ for $15 \mathrm{~min}$ (Gorenje E5352-E2, Velenje, Slovenia).

A total of 45 experimental samples (flour + addition) and 6 control samples were baked for comparison and for colour measurement verification. For instrumental colour assessment, 7 slices from each sample were used.

Image analysis

Wholemeal bread slices of $1 \mathrm{~cm}$ width were photographed by a digital camera of Canon EOS 450D (Canon Europe Ltd., United Kingdom) with time exposition function set to 1/100, ISO 100, focus F 6.3 and the "white balance" (WB) function turned on. The photographs were saved in the lossless RAW format which prevents colour reduction and ensures high image quality. Sample digitization was performed at constant light intensity (intensity level of $1060 \times 1$ ), which was ensured by using a luxmeter (Voltcraft LX -1108). Prior to image analysis, the images were minimized to $2000 \times 1333$ pixels using the Digital Photo Professional Version 3.13.51.1 software (Canon Europa N.V.and Canon Europe Ltd, United Kingdom). Concurrently, the photographs were converted from RAW into the uncompressed TIFF format (Tagged Image File Format).

Colorimetric processing of the digital images was performed using the Adaptive Contrast Control Structure and Object Analyzer version 6.1 (ACC ACCSofo, 2013). All photographs were taken under the same lighting conditions, so that colour changes could be compared. Comparable lighting conditions were achieved by using a photographic box with artificial lighting and a camera set to the manual mode with a set of fixed parameters. Figure 1 (Plate IV) shows the original photograph before it was processed by the Adaptive Contrast Control Structure and Object Analyzer, version 6.1 (ACC ACCSofo, 2013). Subsequently, image segmentation was performed (including identification of the object of interest), which is shown in Fig. 2 (Plate IV).

The measured indicator in the images was pixel mean value (MV) for red, green, and blue colours. Mean value refers to the brightness components of pixels in colour images, where pixel values are arithmetic means of the read (R), green (G), and blue (B) components of pixels of the colour image. Colour was calculated according to the following formula, using the measured values:

$\mathrm{h}=\arctan \frac{\mathrm{MVG}-\mathrm{MVB}}{\mathrm{MVR}-\mathrm{MVB}}$

where $h$ is hue, i.e. the colour, and MVR, MVG, MVB refer to the mean values for red, green and blue. It is a dimensionless quantity. The $\mathrm{h}$ value from the above formula is compared with the pre-determined values: $h=0.0000$ for red, $h=0.4636$ for orange, $h=0.7854$ for yellow, and $h=1.5707$ for green.

\section{Statistical analysis}

A total of 357 photographs of samples were evaluated by means of the image analysis method. The data obtained were processed using the MiniTab software (developed at the State College, Pennsylvania, USA).

The data were subjected to general regression using a general regression model which combines linear regression with a general linear model (Agresti 1990). In general regression, the input data are divided for the purpose of data processing into categorical factors (i.e. the object of study) and continuous numerical factors (variable factor). The categorical factors in the model were the type of flour used and the type of addition. The continuous numerical factor is the relative amount of flour. The output of the mathematical processing of the measured values is the colour of baked breads. Using the above model, it is possible to assess the variability of input data and draw a conclusion regarding the assessment of the colour of bakery products, depending on factors such as flour or addition type.

\section{Results}

\section{Proposition of a regression model for colour calculation}

The results obtained by means of image analysis of model samples were subjected to general linear regression. This step was performed with the aim to verify that data show sufficient variability determined by the type of wholemeal flour (spelt, wheat, rye) as well as by the type of addition used (buckwheat, oat, barley). The verification by means of linear regression shows whether the obtained results reflect the different composition of model samples. Using the regression model it was found that the outlying data regarding control samples, i.e. those which contain either no addition ( $100 \%$ whole meal flour) or no wholemeal flour $(100 \%$ addition) skew the general regression model for colour calculation. This finding 
was supported by calculating the coefficient of determination, which showed data variability of only $45.14 \%$. It should be noted that the higher the coefficient, the higher the informative capability of the analysed data. Considering the fact that the objective of the present study was to determine the impact of varying amounts of additions on the results and to determine the sensitivity of the employed method, the data pertaining to control samples could be excluded from the general regression model testing. Linear regression was carried out for the second time, without the outlier data pertaining to control samples. A modified version of a general linear regression model was created, whose functionality was tested by means of calculating the coefficient of determination, which showed data variability of 95.41 per cent. The remaining 4.59 per cent are determined by factors other than additions, e.g. baking, rising and the methodology of the experiment. Thus, the coefficient of determination helped to verify the usability of the modified general regression model for the purposes of the assessment of colour of bakery products. From the regression model, a linear regression equation for colour calculation was derived. The equation is listed in Table 2. By replacing "flour_rel" in the equation with a number denoting a particular amount of wholemeal flour, we can calculate the colour of the sample for all the addition concentrations.

Table 2. Regression equation for the calculation of colour.

\begin{tabular}{lcc}
\hline Flour & Addition of flour & Regression equation \\
\hline \multirow{2}{*}{ Wheat } & barley & colour $=0.617182-0.0262847 \times$ flour_rel \\
& buckwheat & colour $=0.532971+0.0560830 \times$ flour_rel \\
oat & colour $=0.588694+0.0329437 \times$ flour_rel \\
Spelt & barley & colour $=0.605372+0.0064030 \times$ flour_rel \\
& buckwheat & colour $=0.489789+0.0767779 \times$ flour_rel \\
Rye & oat & colour $=0.613050-0.0269678 \times$ flour_rel \\
& barley & colour $=0.573653+0.0204350 \times$ flour_rel \\
& butwheat & colour $=0.535290+0.0718639 \times$ flour_rel \\
\end{tabular}

*flour_rel (the amount of wholemeal flour in the mixture)

Graphically, the general regression model can be viewed as a system of lines. The direction of each line is determined by the coefficient value, showing changes in colour depending on the changes in the proportion of flour to an addition. The higher the absolute coefficient value, the greater the impact of the flour/addition ratio on the colour of the product. Graphically, the situation is reflected in the greater slope of the line. Alternatively, where the colour of the product is independent of the flour/addition ratio, the near-zero absolute value of the coefficient causes the line to be almost perfectly horizontal.

\section{Effect of oat, barley and buckwheat additions}

Figure 3 shows the general regression model used for the purposes of the assessment of colour of bakery products depending on the additions used. The changing colour indicates changes in the combination of additions. The horizontal line parallel to the x-axis stands for the seeming lack of significance of the flour/addition ratio; on the other hand, lines with a slope (higher than zero) point to a certain level of significance of the ratio. A test of significance was performed in order to verify the significance of the effect of different flour/addition ratios. The test of significance showed that the only combination of wholemeal spelt flour and an increasing amount of barley flour addition (blue colour) was not significant $(P>0.05)$ 
Scatterplot of colour vs flour_rel
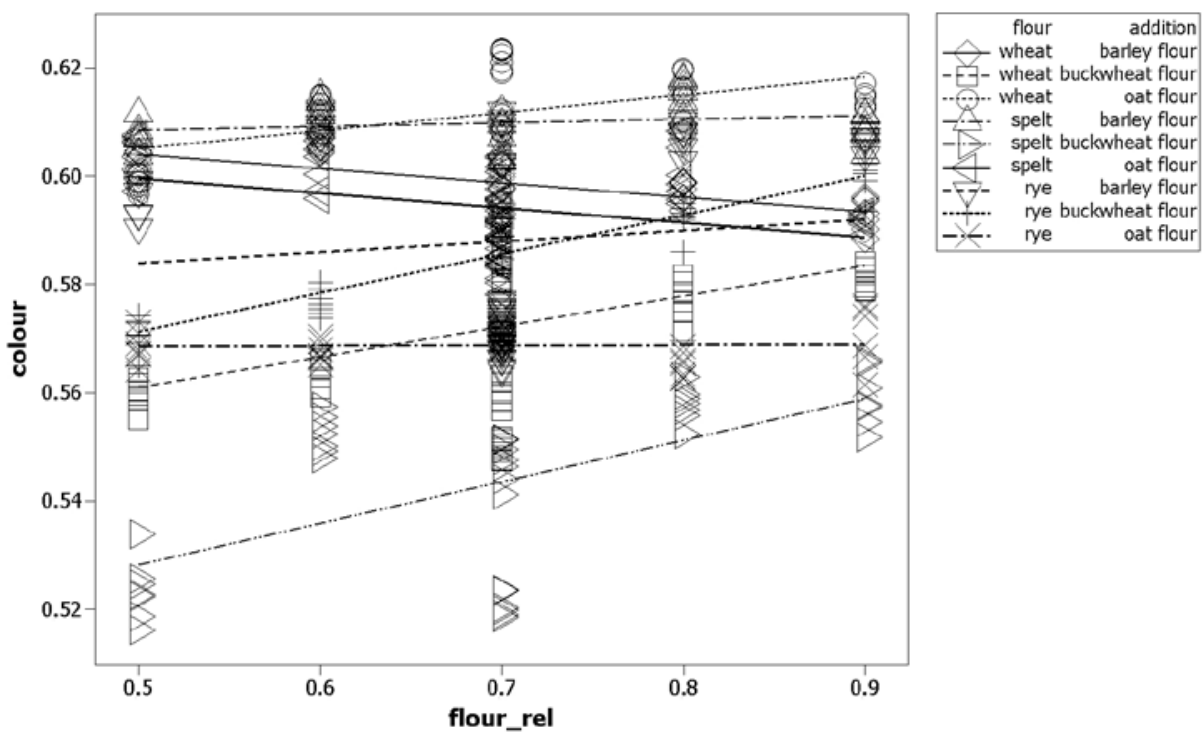

Fig. 3. Linear regression graph for all types of wholemeal flour and addition

\section{Scatterplot of colour vs flour_rel}

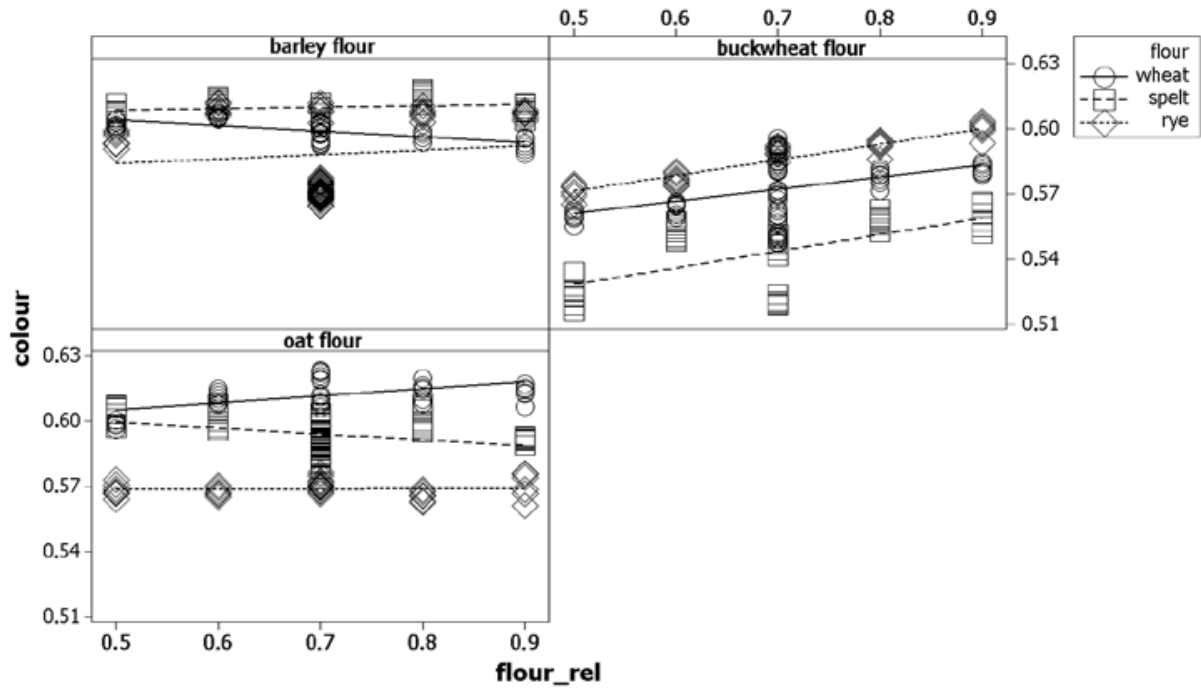

Panel variable: addition

Fig. 4. Linear regression graphs according to flour type

to impact the colour of the product. In order to enhance the clarity of data presentation, the general regression model data were stratified based on the categorical factor (i.e. flour and addition type). The result of the flour-based stratification is presented in Fig. 4. 
From the graph it is clear that, as far as spelt/barley and rye/oat mixtures are concerned, the direction of the line is horizontal, meaning that the influence of the flour/addition ratio in these cases was not found to be significant $(P>0.05)$.

\section{Scatterplot of colour vs flour_rel}

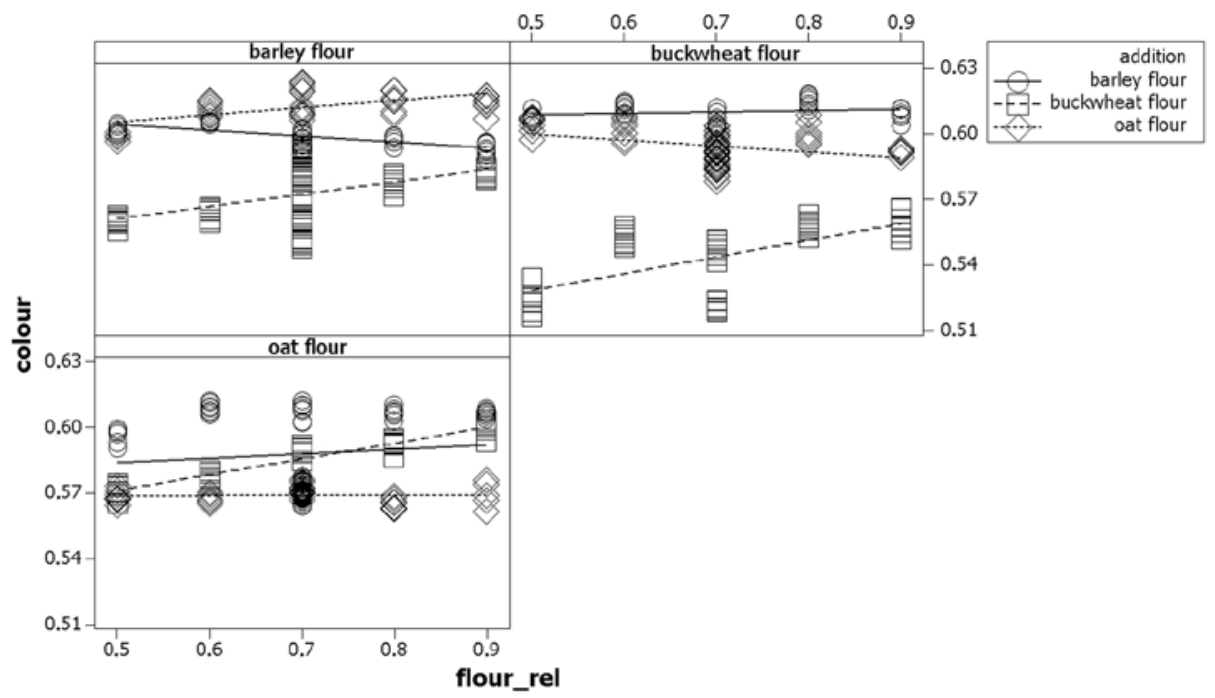

Panel variable: flour

Fig. 5. Linear regression graphs according to addition type

\section{Multi-Vari Chart for colour by flour - addition}

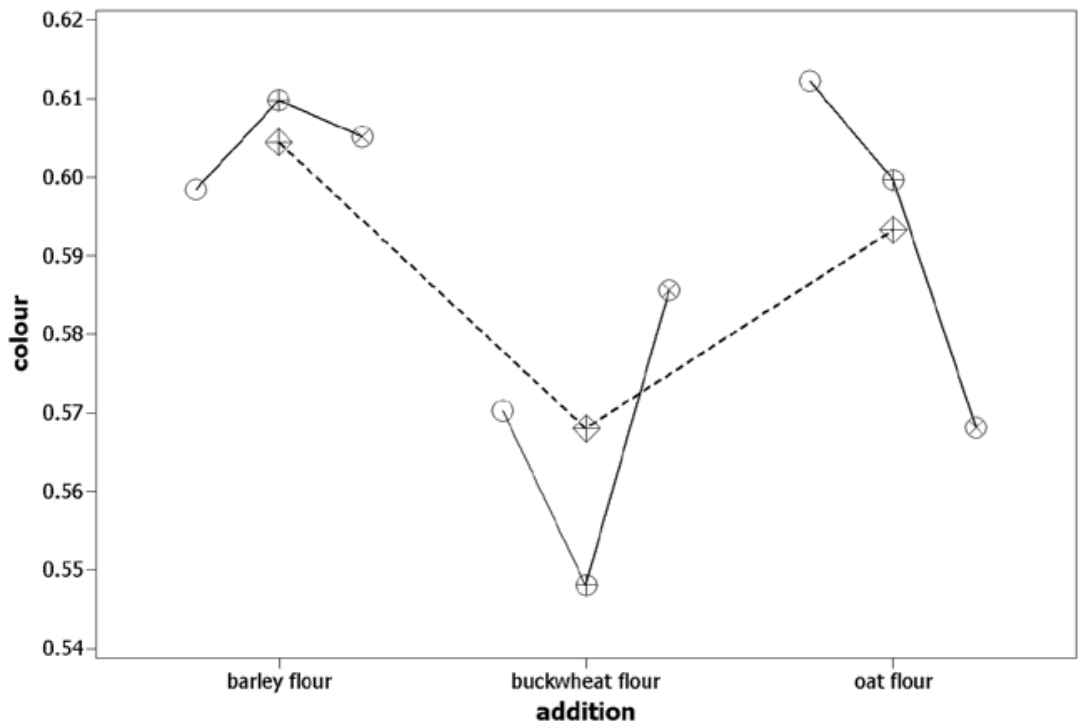

Fig. 6. Dependence of colour on flour and addition type 
Figure 5 shows addition type-based data stratification. As with the flour type-based stratification, it can clearly be seen that influence of barley/spelt and oat/rye ratios on the colour of the product is not significant, for the lines are almost horizontal.

Effect of rye, oat, barley and buckwheat additions (irrespective of the addition/flour ratio)

Disregarding the direction of the lines (ascending, descending, and horizontal) and flour and addition concentrations as in Figs 3,4 and 5, we can view colour as a variable dependent on two categorical variables in the form of flour and addition type (Fig. 6).

From Fig. 6 it is clear that barley additions exhibited the lowest - though still significant $(P<0.05)$ - effect on the colour of the samples. In the group of samples involving barley, the mean colour value ranged from 0.60 (wheat flour) to 0.61 (spelt flour). In the group involving oat additions, however, the colour mean went through substantial changes, ranging from 0.56 for rye flour to 0.61 for wheat flour. Buckwheat additions were somewhere in the middle, the colour mean ranging from 0.55 for spelt flour to 0.58 for rye flour. Fig. 6 clearly shows that the greatest effect on the colour of the samples was that of oat additions. The above measurement results, which are graphically presented in Fig. 6, were subjected to significance test where individual input factors (i.e. flour type [flour] and addition type [addition]) as well as different flour/addition ratios ([flour_rel]) and their interactions were tested for significance using multidimensional scatter plot analysis (ANOVA) (Table 3). The test confirmed the significance $(P<0.05)$ of both the input factors and flour/addition ratios.

Table 3. Results of multidimensional scatter plot analysis (ANOVA).

\begin{tabular}{lrrrrrr}
\hline Source & DF & Seq SS & Adj SS & Adj MS & F & $P$ \\
\hline Regression & 17 & 0.149096 & 0.149096 & 0.008770 & 362.756 & 0.000000 \\
$\quad$ flour & 2 & 0.004047 & 0.000434 & 0.000217 & 8.980 & 0.000163 \\
$\quad$ addition & 2 & 0.073613 & 0.016966 & 0.008483 & 350.875 & 0.000000 \\
flour_rel & 1 & 0.003503 & 0.003503 & 0.003503 & 144.878 & 0.000000 \\
$\quad$ flour*addition & 4 & 0.059419 & 0.003232 & 0.000808 & 33.422 & 0.000000 \\
flour*flour_rel & 2 & 0.000182 & 0.000182 & 0.000091 & 3.774 & 0.024065 \\
$\quad$ addition*flour_rel & 2 & 0.006288 & 0.006288 & 0.003144 & 130.042 & 0.000000 \\
$\quad$ flour*addition *flour rel & 4 & 0.002044 & 0.002044 & 0.000511 & 21.135 & 0.000000 \\
Error & 297 & 0.007181 & 0.007181 & 0.000024 & & \\
Pure Error & 270 & 0.002725 & 0.002725 & 0.000010 & & \\
Total & 314 & 0.156277 & & & &
\end{tabular}

\section{Discussion}

The colour of bakery products was influenced by many factors. Colour formation in bakery productsduringbaking is widelyknownasbrowning(Purlis 2010). Non-enzymatic browning is the general denomination of darkening of a food product due to any reaction not owing to enzymatic activity (Quintas et al. 2007). Non-enzymatic browning is mainly associated with carbohydrate degradation reactions, such as the Maillard and caramelisation reactions (BeMiller and Whistler 1996). The Maillard reaction takes place where reducing sugars and amino acids, proteins and/or other nitrogen-containing compounds are heated together, whereas caramelisation is a term describing a complex group of reactions that occur due to direct heating of carbohydrates, in particular sucrose, and reducing sugars (Fennema 1996). In this paper the bakery products were made for identical conditions. It can be assumed that the original colour of bakery products was influenced by raw materials (content 
components). The impact on the colour of the product was that of wholemeal spelt flour and an increasing amount of barley addition (blue colour). This may have been caused by the high concentration of the relatively colourless polyphenolic substances. Among these, the most important are flavan-3-ols, amino-phenolic compounds, benzoic and cinnamic acid derivatives, and proanthocyanidines (Goupy et al. 1999; Bonoli et al. 2004). In addition, no significance was observed for the combination of wholemeal rye flour and the increasing amount of oat flour, for oats, too, are rich in polyphenolic substances, which include especially a group of flavan-3-ols (Bonoli et al. 2004) (Table 4).

The colour of bakery products is

Table 4. $P$-values of the significance of linear regression directions.

\begin{tabular}{lccc}
\hline & Barley flour & Buckwheat flour & Oat flour \\
\hline Wheat flour & 0.000 & 0.000 & 0.000 \\
Spelt flour & 0.208 & 0.000 & 0.000 \\
Rye flour & 0.001 & 0.000 & 0.817 \\
\hline
\end{tabular}
especially influenced by the presence of fibrous layers - the hull - in the wholemeal flour used. According to Ram and Mishra (2009), the hull is rich in natural pigments, such as polyphenols (anthocyanines in particular) and carotenoids (especially B-carotene and luteins). According to Naczk and Shahidi (2006), these pigments are also present in the aleurone layer and partially in the endosperm layer as well, especially in wheat. The above facts explain why colour is likely to be affected primarily when wholemeal hull-containing flour is used. As it is clear from Table 3, buckwheat exhibited a significant $(P<0.05)$ influence on the colour of all the samples where it was involved. This was caused by rutin (also called rutoside, quercetin-3-O-rutinoside) contents. Rutin is described as a yellow or yellow-green, crystalline, photosensitive substance, wellsoluble in water-free alcohol, methyl alcohol and in alkali hydroxides solution (S weetman 2005). Its presence has a great impact on the colour of the grain.

The use of image analysis for colour evaluation of bakery products was confirmed in many works. A prototype-automated system for visual inspection of muffins was developed by Abdullah et al. (2000). The muffins for colour by visual examination and by development of a machine-reading system coupled with discriminant analysis of the data acquired were evaluated. A classification algorithm separated light from dark-coloured muffins. Applied to 200 samples, the automated system was able to correctly classify $96 \%$ of the pre-graded muffins and $79 \%$ of the ungraded muffins. The algorithm procedure was able to classify muffins at an accuracy level better than $88 \%$ in most cases whereas quality decisions among inspectors varied by 20 to 30\% (Abdullah et al. 2000). Davidson et al. (2001) measured the physical features of chocolate chip biscuits, including size, shape baked dough colour, and fraction of top surface area that was chocolate chip using image analysis. Four fuzzy models were developed to predict consumer ratings based on three of the features. Machine vision has also been used in the assessment of quality of crumb grain in bread and cake products (Sapirstein 1995). Using this technique, the different characteristics influencing the crumb grain were studied.

Based on the results obtained by the present study and presented literature, it can be concluded that the study was successful in confirming the sensitivity of the image analysis method for the assessment of colour of bakery products. The method can thus be implemented in practice, not only in the final inspection procedure in bakery products manufacturing, but also in scientific research. Within the experiment, the image analysis method was modified and subsequently used for the assessment of the colour of bakery products. The measured data were used to develop a general regression model which showed data variability of more than 95 per cent. Disregarding the flour/addition ratios, it was discovered that the factors in the form of wheat, spelt and rye flour, and barley, oat and buckwheat flour additions and their interactions influence the colour of the bakery 
products to a significant extent $(P<0.05)$. As far as the dependence of the colour on the flour/addition ratio is concerned, it was found to be significant $(P<0.05)$ for the combinations of wheat flour with buckwheat, barley and oat mixtures, spelt flour with buckwheat and oat mixtures and rye flour with buckwheat and barley mixtures. Thus, the effect of the additions used on the colour of bakery products has been confirmed.

\section{Acknowledgements}

This research was supported by the project IGA 17/2012/FVHE.

\section{References}

Abdullah MZ, Aziz SA, Mohamed A 2000: Quality inspection of bakery products using a color-based machine visine system. J Food Quality 23: 39-50

Agresti A 1990: Categorical data analysis. Wiley, New York, 576 p.

BeMiller JN, Whistler RL 1996: Carbohydrates. In: Fennema OR (Ed.): Food Chemistry, $3^{\text {rd }}$ edn. CRC Press, New York, pp. 157-224

Bonoli M, Verardo V, Marconi E, Caboni MF 2004: Antioxidant phenols in barley (Hordeum vulgare L.) flour: Comparative spectrophotometric study among extraction methods of free and bound phenolic compounds. J Agric Food Chem 52: 5195-5200

Damez JL, Clerjon S 2008: Meat quality assessment using biophysical methods related to meat structure. Meat Sci 80: $132-149$

Davidson VJ, Ryks J, Chu T 2001: Fuzzy models to predict consumer ratings for biscuits based on digital features. IEEE Transactions on Fuzzy Systems 9: 62-67

Dàvila E, Toldrà M, Saguer E, Carretero C, Parés D 2007: Characterization of plasma protein gels by means of image analysis. LWT-Food Sci Technol 40: 1321-1329

Du CJ, Sun DW 2004: Recent developments in the applications of image processing techniques for food quality evaluation. Trends Food Sci Tech 15: 230-249

Fennema OR 1996: Food Chemistry. CRC Press, New York, 1088 p.

Gerrard DE, Gao X, Tan J 1996: Beef marbling and color score determination by image processing. J Food Sci 61: 145-148

Girolami A, Napolitano F, Faraone D, Braghieri A 2013: Measurement of meat color using a computer vision system. Meat Sci 93: 111-118

Goupy P, Hugues M, Boivin P, Amiot MJ 1999: Antioxidant composition and activity of barley (Hordeum vulgare) and malt extracts and of isolated phenolic compounds. J Sci Food Agric 79: 1625-1634

Gunasekaran S 1996: Computer vision technology for food quality assurance. Trends Food Sci Tech 7: 245-256

Liu Z, Scanlon MG 2003: Predicting mechanical properties of bread crumb. Food Bioprod Process 81: 224-238

Locht P, Thomsen K, Mikkelsen P 1997: Full color image analysis as a tool for quality control and process development in the food industry. In 1997 ASAE Annual International Meeting Technical Papers, ASAE, USA, Paper (No. 973006)

Moghaddam AMR, Rafe A, Taghizade M 2014: Kinetics of color and physical attributes of cookie during deep-fat frying by image processing techniques. J Food Process Pres 38: 1-9

Naczk M, Shahidi F 2006: Phenolics in cereals, fruits and vegetables: Occurrence, extraction and analysis. J Pharm Biomed Anal 41: 1523-1542

Pérez-Nieto A, Chanona-Pérez JJ, Farrera-Rebollo RR, Gutiérrez-López GF, Alamilla-Beltrán L, CalderónDomínguez G 2010: Image analysis of structural changes in dough during baking. Food Sci Technol-Leb 43: 535-543

Purlis E 2010: Browning development in bakery products - a review. J Food Eng 99: 239-249

Quintas MAC, Brandão TRS, Silva CLM 2007: Modelling colour changes during the caramelisation reaction. J Food Eng 83: 483-491

Ram S, Mishra B 2009: Cereals: Processing and Nutritional Quality. New India Publishing, New Delhi, 314 p.

Sapirstein HD 1995: Quality control in commercial baking: Machine vision inspection of crumb grain in bread and cake products. In: Food processing automation IV Proceedings of the FPAC Conference. ASAE, Michigan, USA, 2950: 4985-9659

Scanlon MG, Zghal MC 2001: Bread properties and crumb structure. Food Res Int 34: 841-864

Sweetman S 2005: Martindale: the complete drug reference. Pharmaceutical Press, London, 2493 p.

Tao Y, Heinemann PH, Varghese Z, Morrow CT, Sommer HJ 1995: Machine vision for color inspection of potatoes and apples. Transactions of the ASAE 38: 1555-1561

Van Dyck T, Verboven P, Herremans E, Defraeye T, Van Campenhout L, Wevers M, Nicolaï B 2014: Characterisation of structural patterns in bread as evaluated by X-ray computer tomography. J Food Eng 123: 67-77 
Velez-Ruiz JF, Sosa-Morales ME 2003: Evaluation of physical properties of dough of donuts during deep-fat frying at different temperatures. Int J Food Properties 6: 341-353

Yam KL, Papadakis SE, Spyridon E 2004: A simple digital imaging method for measuring and analyzing color of food surfaces. J Food Eng 61: 137-142

Zheng C, Sun DW, Zheng LY 2005: Correlating colour to moisture content of large cooked beef joints by computer vision. J Food Eng 77: 858-863

Ziaiifar AM, Achir N, Courtois F, Trezzani I, Trystram G 2008: Review of mechanisms, conditions, and factors involved in the oil uptake phenomenon during the deep-fat frying process. Int J Food Sci Tech 43: 1410-1423 
Plate IV

Čáslavková P. et al.: Colour change ... pp. S111-S120

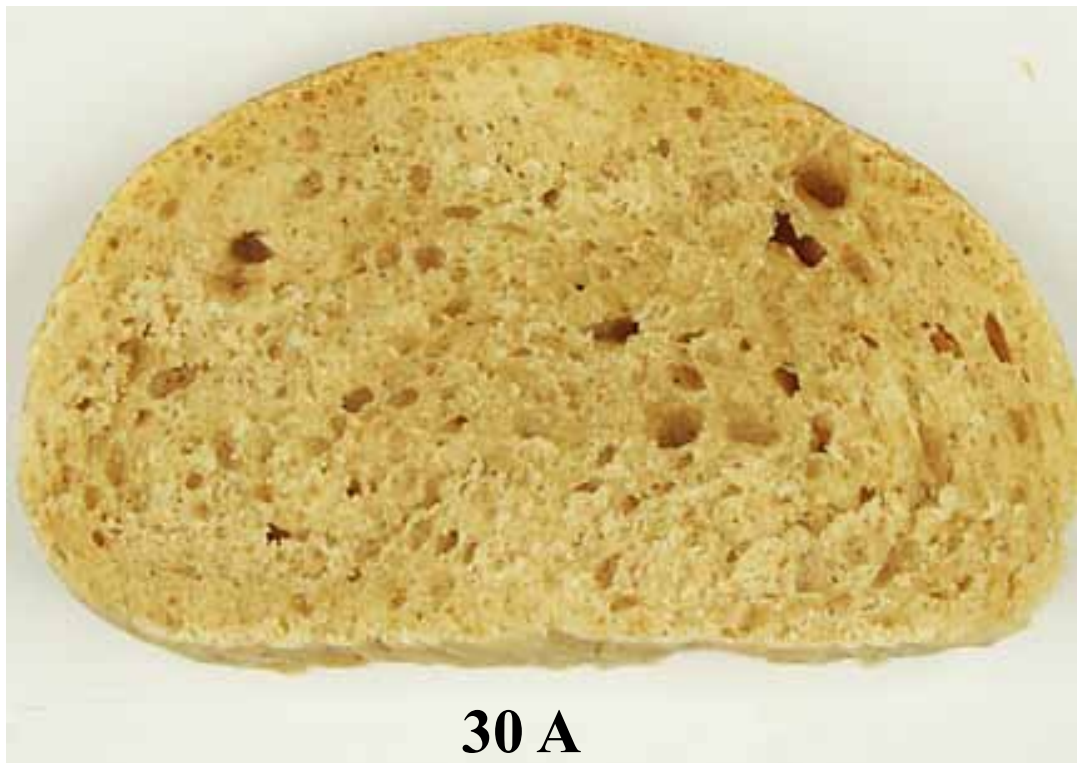

Fig. 1. Original image of bread

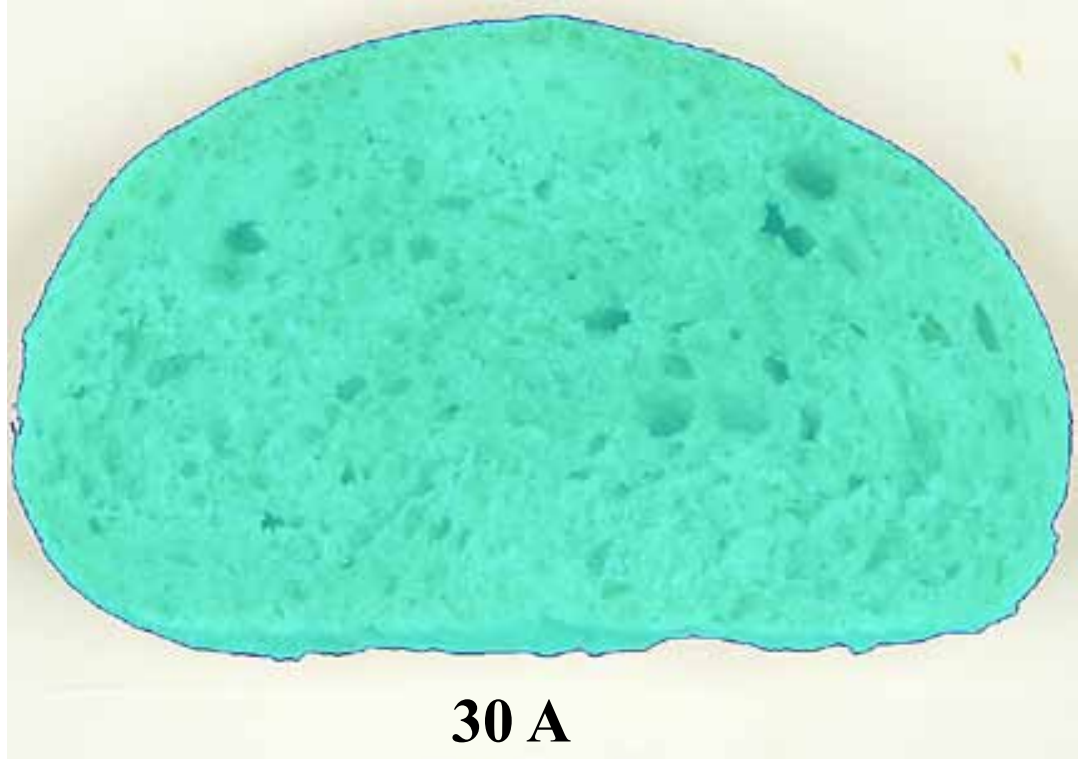

Fig. 2. Image segmentation of bread 